1997 Particle Accelerator Conference, Vancouver, B.C., Canada, May 12-16, 1997

\title{
Modifying CERN SPS Cavities and Amplifiers for Use in RHIC
}

\section{R. Connolly, J. Aspenleiter, S. Kwiatkowski}

Brookhaven National Lab, Upton, New York 11973

\section{RECEIVED}

JUN 251997

\begin{abstract}
A system of ten $\mathrm{rf}$ cavities operating at $197 \mathrm{MHz}$ will provide longitudinal focusing during beam storage in the Relativistic Heavy Ion Collider (RHIC). The cavities and tetrode amplifiers are from CERN where they had been used in the Super Proton Synchrotron to accelerate leptons for injection into LEP. The amplifier-cavity system had an impedance pole about $3 \mathrm{MHz}$ below cavity resonance which was a possible source of oscillation with if feedback. This was not a problem at CERN because the cavities were operated without feedback. The impedance pole was moved lower in frequency by extending the length of the drive line. When this was done it was no longer possible to tune the amplifier to give a good match to the drive loop resulting in about $50 \%$ anode efficiency. In the class of operation we are using, an efficiency of $65 \%-70 \%$ is expected. A good match was achieved by increasing the loop coupling from $16 \Omega$ to $19 \Omega$.
\end{abstract}

\section{Introduction}

The Relativistic Heavy Ion Collider (RHIC) at Brookhaven National Lab will accelerate and store beams ranging from protons to gold nuclei [1]. One system of four rf cavities operating at $28 \mathrm{MHz}$ [2] accelerates the beam from injection energy to storage energy, and a system of ten cavities operating at $197 \mathrm{MHz}$ provides longitudinal focusing during storage. The storage system cavities and tetrode amplifiers are from the Super Proton

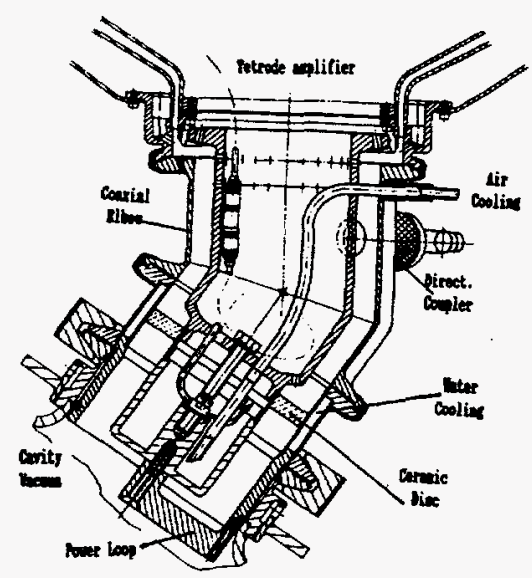

Figure 1. The transmission line connecting the amplifier to the cavity. This figure is copied from reference 3.
Synchrotron at CERN where they accelerab losutr injection into LEP [3].

The amplifier-cavity system has an impedance pole about $3 \mathrm{MHz}$ below cavity resonance which is a possible source of oscillation with if feedback. At CERN the cavities were operated without feedback and care was taken to avoid external feedback, so the impedance pole was not a problem [4].

Experiments were conducted at RHIC to move this pole away from cavity resonance. We found that the pole could be moved lower in frequency by increasing the length of the final drive line. Evidently the drive line had been made quite short because of space limitations in the SPS tunnel. When the longer drive line was installed it was no longer possible to tune the amplifier to give the required impedance transformation, limiting the amplifier to about $50 \%$ anode efficiency. The efficiency was increased to about $70 \%$ by increasing the loop coupling from $16 \Omega$ to $19 \Omega$. This paper describes these experiments and the performance results.

\section{Impedance Pole}

Figure 1 shows the $16 \Omega$ drive line with the base of the amplifier clamped to the flanges on the top of the coaxial elbow and the drive loop installed in the cavity. The line has forward- and reverse-power directional couplers and the cavity has small pickup loops. Two $S_{21}$ network analyzer traces, fig. 2 , were made by driving the amplifier with the analyzer.

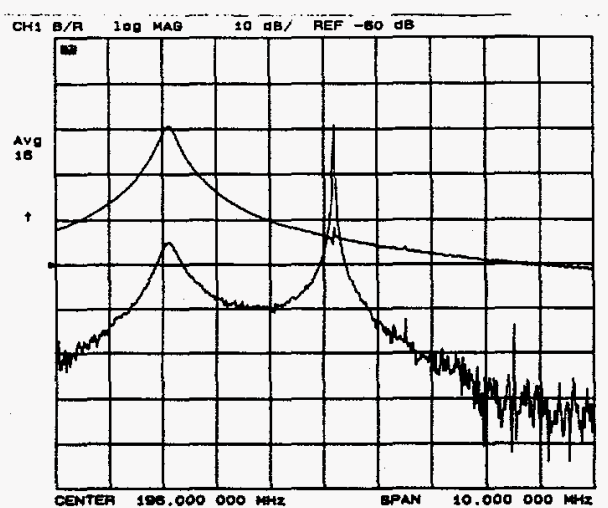

Figure 2. Network analyzer traces showing the impedance pole and cavity resonance. Top trace is the signal from the forward-power coupler in the drive line, and the bottom trace is from a loop inside the cavity. The cavity was tuned to 196 $\mathrm{MHz}$ when these measurements were made. 
The top trace is the signal from the forward-power coupler in the drive line and the bottom trace is the signal from one pickup loop. In the cavity, the power received at the pole frequency is only $25 \mathrm{~dB}$ lower than at cavity resonance. With $\mathrm{rf}$ feedback this resonance can be the same or larger than the cavity resonance.

The first experiment was to separate the amplifier from the drive line flange and to short the inner and outer conductors at the amplifier base with copper tape. A network analyzer and broad-band amplifier were used to drive the amplifier and the signal was picked up on a diagnostic probe at the base of the amplifier. The result, fig. 3 , shows that the amplifier transforms an electrical short at its output to impedance poles which ane symmetrical about $197 \mathrm{MHz}$. Since the drive loop is a short circuit off resonance this shows that the pole does not result from the impedance transformation in the amplifier.

Next an adapter was placed on the drive line flange and an $S_{11}$ measurement was made of the impedance presented to the amplifier. The network analyzer measurement showed the electrical length of the transmission line to be about $3 / 8 \lambda$ giving an offresonance impedance which is capacitive. By adding a phase offset equivalent to $19.4 \mathrm{~cm}$ of transmission line at $197 \mathrm{MHz}$ the transformed impedance presents an impedance zero off resonance.

Reference 4 describes the impedance transformation within the amplifier as being approximately a $\lambda / 4,3 \Omega$ transmission line in series with a $\lambda / 4,18.5 \Omega$ line. PSPICE was used to calculate the impedance of a short circuit transformed through a $3 / 8 \lambda$ section of $16 \Omega$ line in series with the two $\lambda / 4$ lines of the amplifier. This calculation gives poles at 197 and $232 \mathrm{MHz}$ and both move lower in frequencies when the $16 \Omega$ line is lengthened. When the line is $\lambda / 2$ long the upper and lower poles are symmetric around $197 \mathrm{MHz}$.

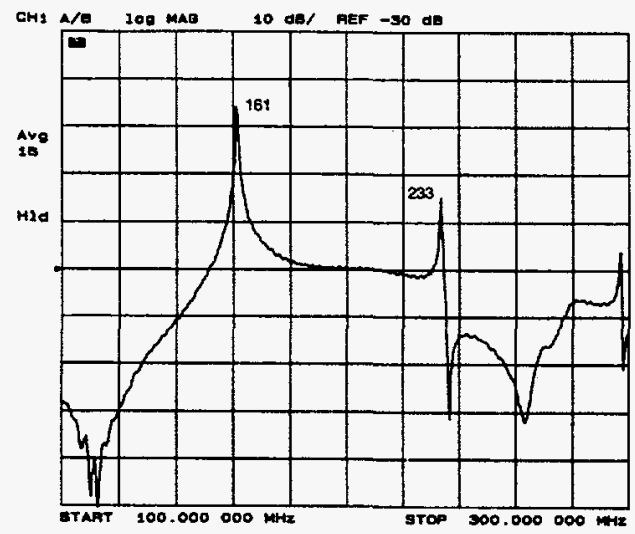

Figure 3. Anode impedance as a function of frequency with an electrical short across the output of the amplifier.
The drive-loop transmission line was lengthened by adding a $17.1 \mathrm{~cm}$ insert in the coaxial elbow section. This insert initially was made $19.4 \mathrm{~cm}$ but measurements made before the pieces were welded indicated it was too long. With the longer line installed the impedance poles were 12 $\mathrm{MHz}$ below and $18 \mathrm{MHz}$ above resonance. The initial length of $19.4 \mathrm{~cm}$ would have placed them symmetrically about the resonance.

\section{Amplifier efficiency}

After the drive line was extended it was no longer possible to get the required power from the tetrode without exceeding the tube specification for power dissipation on the screen. A storage cavity has a shunt impedance of 8.5 $\mathrm{M} \Omega$ and requires about $60 \mathrm{~kW}$ of if power to produce 1 MV in the gap. To deliver $60 \mathrm{~kW}$ without drawing excessive screen current requires the loop impedance be transformed to an anode impedance of about $625 \Omega$. This transformation is accomplished by two sections of transmission line in the amplifier base which approximate $\lambda / 4$ transformers of $3 \Omega$ and $18.5 \Omega$ connected in series.

The tetrode amplifier that drives the cavity is operated in class $A B$ with the grid biased at $-200 \mathrm{~V}$, the screen at $900 \mathrm{~V}$ and the anode at $10 \mathrm{kV}$. At full power the conduction angle is $190^{\circ}$ and the tetrode should give $\sim 70 \%$ efficiency. We measured $54 \%$ efficiency (see table) on a test stand consisting of a $50 \Omega$ water-cooled load transformed to $16 \Omega$ by a $\lambda / 4$ transformer of $Z_{t}=28.3 \Omega$. To increase the efficiency it was necessary to measure the loop-anode impedance transformation from the operating parameters of the tube.

For small anode if voltages the electron current in a tube varies with grid voltage approximately as,

$$
\mathrm{I}(\mathrm{t}) \propto\left(\mathrm{V}_{\mathrm{g} 0}+\mathrm{V}_{\mathrm{g} 1} \cos \omega \mathrm{t}\right)^{1.5}
$$

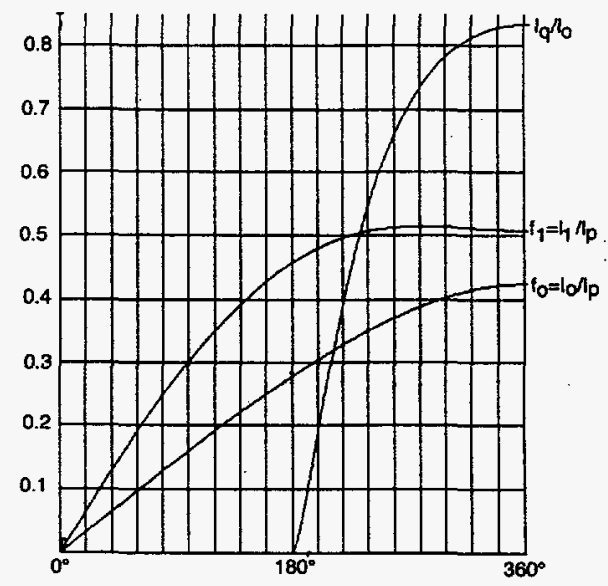

Figure 4. Tube current form factors calculated by $\mathrm{W}$. Pirkl. Bottom axis is conduction angle of tube. All measurements were made with an angle of $190^{\circ}-200^{\circ}$. 
where $\mathrm{V}_{\mathrm{g} 0}$ is the grid bias voltage and $\mathrm{V}_{\mathrm{gl}}$ is the grid drive amplitude. This expression can be used to calculate the Fourier components of the current [5]. The $d c$ and if fundamental components are,

$$
\begin{aligned}
& I_{0}=\frac{1}{T} \int_{0}^{T} I(t) d t=I_{P} f_{0} \\
& I_{1}=\frac{2}{T} \int_{0}^{T} I(t) \cos (\omega t) d t=I_{P} f_{1}
\end{aligned}
$$

where $I_{p}$ is the peak current during the $r f$ cycle. These form factors, $f_{0}$ and $f_{1}$, are plotted in fig. 4 together with a curve of quiescent current divided by anode current, $I_{q} I_{0}$. We measured the ratio $I_{q} / I_{0}$ and read the conduction angle from the graph. The ratio $f_{1} / f_{0}$ could then be determined from the graph and the if current, $I_{1}$, calculated as the anode current times this ratio. The tube power and anode current were measured and the impedance calculated from $\mathrm{P}=\mathrm{I}_{1}{ }^{2} \mathrm{R} / 2$.

A series of measurements was made on the test stand in which output power was measured as both the frequency and the amplifier tuning position were varied. The tube socket can be raised and lowered for tuning and it was not known whether this changed only the frequency or both the frequency and transformed impedance. Figure 5 shows the family of curves generated. For all of these measurements the anode current was $3.1 \mathrm{~A}$ and the quiescent current was $0.6 \mathrm{~A}$ giving a ratio of $f_{1} / f_{0}$ equal to 1.52. All of the tuning curves peak at $6.1 \mathrm{~kW}$ showing the tuning changes only the frequency of the impedance transformation. A power of $6.1 \mathrm{~kW}$ with an $\mathrm{rf}$ current of $4.7 \mathrm{~A}$ gives an impedance of $550 \Omega$. The same analysis on other data sets gave values in the range of $515 \Omega-550 \Omega$. From these measurements we concluded that the amplifier transforms $16 \Omega$ to about $525 \Omega$.

The test stand presents an impedance to the amplifier equal to $\left(Z_{t}\right)^{2} / 50$. The impedance of a coaxial line increases as the diameter of the center conductor decreases so we were able to increase the impedance presented to the amplifier in $1 \Omega$ steps by machining down the inner conductor of the $\lambda / 4$ transformer. The measured efficiency peaked at $20 \Omega$, however the screen current started to get very high. We chose a loop impedance of $19 \Omega$.

\section{Conclusion}

The loop was rotated to give $19 \Omega$ coupling and the drive-line extension was installed. The cavity was then conditioned to a peak gap voltage of $1.0 \mathrm{MV}$ at which time the measurements in the third column of the table were made. These two modifications have increased the amplifier efficiency from about $50 \%$ to about $70 \%$ and have moved the impedance pole $12 \mathrm{MHz}$ away from the cavity resonance.

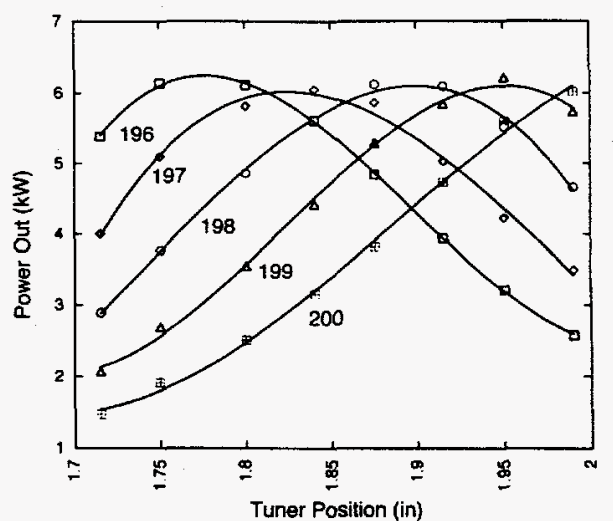

Figure 5. Measured power as a function of tuner position for five frequencies. Tuner changes the frequency of maximum anode impedance but not the magnitude.

Comparison of amplifier parameters reported by CERN [4], those measured at BNL on $16 \Omega$ load, and those measured on cavity after modifications. The final efficiency of $73 \%$ is from a single measurement and is probably a little too high.

\section{CERN $16 \Omega$ load Final}

$\begin{array}{llll}\text { Anode voltage } & 10 \mathrm{kV} & 10 \mathrm{kV} & 9.8 \mathrm{kV} \\ \text { Anode quiescent current } & 0.5 \mathrm{~A} & 0.5 \mathrm{~A} & 0.5 \mathrm{~A} \\ \text { Anode current } & 9.4 \mathrm{~A} & 9.95 \mathrm{~A} & 7.77 \mathrm{~A} \\ \text { Screen grid voltage } & 900 \mathrm{~V} & 900 \mathrm{~V} & 900 \mathrm{~V} \\ \text { Screen grid current } & 320 \mathrm{~mA} & 405 \mathrm{~mA} & 150 \mathrm{~mA} \\ \text { Control grid voltage } & -200 \mathrm{~V} & -200 \mathrm{~V} & -200 \mathrm{~V} \\ \text { RF output power } & 62 \mathrm{~kW} & 53 \mathrm{~kW} & 57 \mathrm{~kW} \\ \text { RF drive power } & 1.8 \mathrm{~kW} & 1.75 \mathrm{~kW} & 1.44 \mathrm{~kW} \\ \text { Gain } & 15.4 \mathrm{~dB} & 14.8 \mathrm{~dB} & 16.0 \mathrm{~dB} \\ \text { Anode efficiency } & 64 \% & 54 \% & 73 \%\end{array}$

\section{Acknowledgement}

The authors benefited from discussions with Ralph Sanders, Mike Brennan, and Alessandro Ratti. Mike Witte operated the test stand for much of this work. This work was performed under the auspice of the U.S. Department of Energy.

\section{References}

1. "RHIC Design Manual", (Brookhaven National Laboratory, Upton, NY 1996)

2. J. Rose, et.al., "The RHIC $28 \mathrm{MHz}$ RF System," these proceedings.

3. P.E. Faugeras, et.al., "The New RF System for Lepton Acceleration in the CERN SPS," Proc. 1987 IEEE PAC Conference, p. 1719

4. W. Herdrich and H.P. Kindermann, "RF Power Amplifier for the CERN SPS Operating as LEP Injector," Proc. 1985 IEEE PAC Conference, p.2794.

5. W. Pirkl, private communication 


\section{DISCLAMMER}

Portions of this document may be illegible in electronic image products. Images are produced from the best available original document. 


\section{DISCLAIMER}

This report was prepared as an account of work sponsored by an agency of the United States Government. Neither the United States Government nor any agency thereof, nor any of their employees, makes any warranty, express or implied, or assumes any legal liability or responsibility for the accuracy, completeness, or usefulness of any information, apparatus, product, or process disclosed, or represents that its use would not infringe privately owned rights. Reference herein to any specific commercial product, process, or service by trade name, trademark, manufacturer, or otherwise does not necessarily constitute or imply its endorsement, recommendation, or favoring by the United States Government or any agency thereof. The views and opinions of authors expressed herein do not necessarily state or reflect those of the United States Government or any agency thereof. 